https://helda.helsinki.fi

\title{
Introduction
}

\section{Nagatsu, Michiru}

$\mathrm{T} \& \mathrm{~T}$ Clark

2019-05-30

Nagatsu , M \& Ruzzene , A 2019 , Introduction . in M Nagatsu \& A Ruzzene (eds) , Contemporary Philosophy and Social Science : An Interdisciplinary Dialogue . T \& T Clark, London , pp. 1-8 . https://doi.org/10.5040/9781474248785-006

http://hdl.handle.net/10138/325231

https://doi.org/10.5040/9781474248785-006

draft

Downloaded from Helda, University of Helsinki institutional repository.

This is an electronic reprint of the original article.

This reprint may differ from the original in pagination and typographic detail.

Please cite the original version. 


\title{
Introduction
}

\author{
Michiru Nagatsu and Attilia Ruzzene
}

Philosophy of social science is a small but vibrant field, which is attested by the number of handbooks and companions: Turner and Roth (2003), Jarvie and Zamora Bonilla (2011), Kincaid (2012), Kaldis (2013), and McIntyre and Rosenberg (2017). The maturity of the field is suggested by the standard textbooks that have been continuously revised-Hollis (1994, revised and updated in 2002), Elster (2015, originally published in 1989), and Rosenberg (2016, 5th edition, originally published in 1988) - as well as standard readers, both classic (Martin and McIntyre, 1994) and contemporary (Steel and Guala, 2011). Two edited volumes from Cambridge (Mantzavinos, 2009) and Oxford (Cartwright and Montuschi, 2014) add to these collections.

One will notice in this literature a gradual shift of focus from the demarcation question of whether social science can be a proper science-despite the peculiar nature of the mental and the social-to the questions concerning actual social scientific practices, such as experimentation, model-building, problem-solving, and evidential reasoning. This shift is in line with the so-called practical turn in the philosophy of science. Accordingly, some philosophers have started adopting a range of empirical approaches including bibliometric, ethnographic, case-based, and experimental methods to study practices. We can call this an empirical turn. Although the practical and empirical turns are sometimes misleadingly interpreted as sociological turns, these turns have not changed philosophers' main interests in ontological, conceptual, and methodological issues in science; rather, they have enriched empirical bases for philosophizing by enriching the kind of methods to obtain data.

Ambitions of the empirical philosophy of social science in practice thus construed include informing and improving social scientific practices. However, there has not been a systematic effort on the part of philosophers to increase direct engagement with practicing social scientists. This book is a modest attempt to initiate such a move. Specifically, it does so by adopting a dialogical template: we invited philosophers and social scientists to engage each other and see in what form and to what extent they could be partners in the same conversation. Admittedly, the dialogical format is not new in the philosophy of social science (e.g., Little 1995; Mantzavinos 2009). However, this book is different from these in a crucial respect. While Mantzavinos (2009) and Little (1995) had social scientists comment on philosophers' views on social sciences, we decided to reverse the roles. Chapters are written by social scientists with the purpose 
of showcasing their innovative research, while philosophers partake in the exchange by providing commentaries (all commentaries, except one, are written by philosophers). Social scientists thus offer an entry point for the conversation. We hoped that this "social science first, philosophy second" approach would elicit a different kind of dialogue between the two research communities. In particular, we hoped that it would encourage philosophers to engage with scientific practices head on, more directly, thoroughly, and seriously than when they are free to philosophize about social science.

Have our expectations been met? What kind of materials have social scientists brought to the table? And what kind of responses have philosophers provided? In what follows, we summarize our findings in the form of a quasi-scientific report.

\section{Methods}

We identified an initial pool of approximately twenty social scientists on the basis of our background knowledge, interests, and networks, whose work we thought was suitable and exciting because of its theoretically and methodologically innovative features. We approached them by e-mail, explicitly requesting them to expose the innovative aspects of their work. They were also informed that a philosopher who specializes in relevant fields would provide a detailed commentary. Thirteen social scientists out of this initial pool showed interest in our initiative and accepted to participate in it. One scholar agreed to contribute, but never followed up. One had to be excluded due to misunderstandings about the focus of the chapter. As a result, we obtained eleven manuscripts. The manuscripts went through anonymous reviewing processes and a round or two of revision, some minor and others major. After the manuscripts have been completed, we asked philosophers of social sciences with relevant expertise to provide critical commentaries. We the editors substituted as commentators on two chapters for which we could not find philosophers suitable to the task or willing to participate. The editors have reviewed and commented on the commentaries, which have been finalized after a round or two of revision (each editor's commentary was reviewed by the other).

\section{Results}

What kind of trends did we find in this exchange? First, we found that some of the social scientists have well-articulated philosophical concerns. They grapple with the same philosophical and methodological questions that philosophers of social science discuss, such as the ontology of the social world or the methodology of causal inference. In these domains, philosophical and social scientific questions largely coincide. The exchange between social scientists' contributions and philosophers' responses is, as a result, not only smooth but also mutually enriching since it provides partly different answers to what are in fact very similar questions. Thus, the philosopher and the social scientist talk to each other in a way that enables them to advance a shared agenda. We see this kind of exchange exemplified, for instance, by David Waldner and Daniel Steel 
who provide alternative interpretations of process tracing while trying to resolve what they both recognize as the problematic aspects of a specific practice. In a similar vein, Nancy Cartwright argues for an extension of Michael Woolcock's proposal to use mixed methods in policy evaluation so as to include a broader population of interventions.

These productive exchanges suggest that philosophers are already informing and improving scientific practices in some domains, together with social scientists. The two research communities happily overlap in such domains. This overlap is due partly to philosophers' increasing attention to scientific practice, but also due to the problems in question being inherently philosophical, disposing the social scientists to adopt philosophical approaches in formulating or framing the problem they are working on.

In a second-perhaps more traditional-kind of exchange, philosophers elaborate, clarify, or even correct social scientists' characterizations of their own practices. Sometimes the philosopher provides a sort of philosophical backbone to the interpretation outlined by the social scientist. This would be, for instance, the case of Stephen Turner commenting on Michael Carleheden's discussion on the role of social theory in sociology. Other times the philosopher provides a rationale for the practice at hand, clarifying the methodological and theoretical import of the innovation advocated by the social scientist. Exemplary of this type of exchange is Daniel Little's commentary on Wendy Olsen's discussion of the role of critical realism in social statistics. In yet other cases, the philosopher, while seeing the reasons and goals behind a given practice, points out underlying misunderstandings that could impair or obfuscate its potential. This is illustrated by Petri Ylikoski's commentary on the discussion of temporal modeling by Tommaso Venturini. In all these cases the philosopher's contribution amounts to sharpening the philosophical underpinning of the practice in a way that not only makes it philosophically sounder but also clears the path where further benefits and developments could or should be sought.

In these cases, we find that some of the standard analytic and conceptual tools developed in the philosophy of (social) science have proved useful. These toolsrealism, the micro-macro distinction, social ontology, under-determination, scientific pluralism, interpretivism versus positivism, and so on-do not directly solve social scientific problems, but they are useful in helping us understand practice better

\section{Discussion}

In this section, we briefly address some of the limitations of our study and suggest an area we think philosophers of social science need to study. As noted in the introduction, the main goal of the book was to facilitate a new kind of dialogue between social scientists and philosophers led by the former. This design probably created a self-selection bias toward those social scientists who are more likely to be philosophically minded than the average researcher in their field. We think that this bias served our purpose, namely to initiate and facilitate collaborative and critical interactions between the two communities. But in general, an empirical study of social scientific practices should pay attention to the self-selection bias. 
Potentially problematic is our selection of the target social science disciplines and fields. Our selection is by no means a balanced and comprehensive sample from the state of the art in the social sciences. It has a clear bias toward economics and related fields, such as business research, econometrics, evaluation of development policies, ecological economics, and, to a less extent, sociology and political science. Other fields such as anthropology, psychology, social epidemiology, and so on are absent. This is partly due to the bias in the editors' areas of expertise, but also it reflects the bias of the current philosophy of social science in general. ${ }^{1}$ We have no intention to endorse such a bias as a good thing. Rather, we simply acknowledge that we, as the editors, are part of the bias and encourage the reader to consult the handbooks and edited volumes mentioned in the introduction that address this selection bias to some extent.

Whereas the biases discussed above can be justified by appealing to the primary purpose of the book and the path-dependence of the literature in which the project is embedded, there is another, more important, limitation that we should address here: we could not cover many of the emerging new methodological innovations that are somehow philosophically relevant and likely to trigger the interest and reactions of philosophers of the social sciences in the near future, if they haven't done so already. Below we would like to briefly discuss one such area of relevance, big data, to indicate that there is much more uncharted area of potential mutual engagement between social scientists and philosophers.

The digital revolution and the advent of big data generated changes across social sciences. Specialized journals have been founded (e.g., Big Data and Society) and established journals have guested special issues dedicated to the topic (e.g., International Journal of Sociology, Journal of Psychological Methods, Journal of Business \& Economics Statistics, Political Science and Politics, just to name a few). This turn has caused a broad range of novelties. First, the most tangible and immediate effect is that a massive amount of data, which are different in relevant respects from traditional data (Leney 2004; Kitchin 2014; Leonelli, 2014; Kitchin and McArdle 2016), have become available, constituting an additional source of evidence for the phenomena and processes that have been already studied, for example, use of web search data to estimate unemployment: Ettredge et al. (2005); D’Amuri (2009); Fondeur and Karamé (2013); and Askitas and Zimmermann (2015) Second, the turn has generated novel social, economic, and political phenomena worth investigating on their own. Consider as an example the work of political scientist Jonathan Bright (2018), who studies how political fragmentation in social media increases radicalization and how social media affect patterns of news sharing (Bright 2016), or the work of media scholar Zizi Papacharissi (2010), who theorizes on how digital technologies have shifted civic engagement from the public to the private sphere and introduces the concept of affective publics to explain how social movement use digital media to generate engagement and make their voice matter in politics (Papacharissi 2015). The third novelty concerns methodology. The digital revolution makes the traditional tools of research more powerful and also generates new ones, giving rise to new fields such as digital humanities. Finally, the digital revolution has stimulated the critical approach 
in the social sciences. For example, the Gender and ICT research group at the Open University of Catalonia was established in 2006 to study data intensive research methods from a feminist perspective. One of its goals is to investigate the ways in which new data conceptualizations, technologies, and related social practices can be used for transformative societal changes.

Philosophers of science have only recently started paying attention to the digital turn in the sciences (with the notable exception of Sabina Leonelli, who has published extensively on the advent of digitization and big data mainly in the biological sciences). Other philosophical contributions have so far focused on big data as forecasting tools (Hosni and Vulpiani 2017), theory-ladenness (Pietsch 2015), epistemology and causality (Canali 2016), modeling in data-intensive science (Pietsch 2016), and philosophy of information (Floridi 2012). However, contributions focusing on the social sciences are still scant. Much more investigation is needed into how social mediatization contributes to the dissemination of scientific knowledge and its transformation (e.g., by reducing its complexity), and how this will affect society and policy making at large.

As the big data case indicates, social scientific practices are changing in response to the technological and societal changes. Philosophers and social scientists can work together to understand and respond to these changes. We hope this book will help facilitate a collaborative dialogue between the two communities.

\section{How to Use This Book}

We will close this introduction by offering some guide on how to use this volume in courses on the philosophy of social science. The instructor can use this book as a philosophical guide to three salient trends in social sciences in practice: issues raised by the plurality of approaches, disciplines, and theories (Part One: Chapters 1-3); debates over choices of one method over another and the need to mix multiple methods (Part Two: Chapters 4-8); and issues around the methodology and foundation of social scientific explanation and theorizing (Part Three: Chapters 9-11). Alternatively, the reader can organize chapters according to the philosophical concepts that have been used by commentators. For instance, mechanism and social causation (Chapters 7, 8, and 11), causal inference (Chapters 4, 5, and 9), theory choice (Chapters 3 and 10); scientific pluralism (Chapters 1 and 2), and interpretivism (Chapter 6). In either way, we recommend the instructor to require students to read a chapter and its commentary as a set and have them discuss whether the philosopher and the social scientist talk past each other, or their exchange is fruitful.

We have two cautions. The book highlights the domains where we think potential gains from exchange between social scientists and philosophers are high, rather than evenly covering all the areas in the social sciences. The second caution concerns the level. Some chapters and commentaries presuppose some familiarity with technical details of theories, methods, and philosophical concepts. The instructor may want to provide introductory materials before assigning those chapters to students. 


\section{Note}

1 For example, Philosophy of Economics is by far the biggest subcategory under the category Philosophy of Social Science at PhilPapers.org (11,324 entries out of 59,698 as of September 2018). Note that the other bigger two subcategories, Philosophy of Education $(27,438)$ and Philosophy of Law $(17,915)$, are usually not considered to be part of the Philosophy of Social Science.

\section{References}

Askitas, N., and K. F. Zimmermann. 2015. "The Internet as a Data Source for Advancement in Social Sciences." International Journal of Manpower 36 (1): 2-12.

Bright, J. 2016. "The Social News Gap: How News Reading and News Sharing Diverge." Journal of Communication 66 (3): 343-65.

Bright, J. 2018. "Explaining the Emergence of Political Fragmentation on Social Media: The Role of Ideology and Extremism." Journal of Computer-Mediated Communication 23 (1): 17-33.

Canali, S. 2016. "Big Data, Epistemology and Causality: Knowledge In and Knowledge Out in Exposomics." Big Data \& Society 3 (2): 205395171666953.

Cartwright, N., and E. Montuschi, eds. 2014. Philosophy of Social Science: A New Introduction. Oxford: Oxford University Press.

D’Amuri, F. 2009. Predicting Unemployment in Short Samples with Internet Job Search Query Data. Italy: University Library of Munich.

Elster, J. 2015. Explaining Social Behavior: More Nuts and Bolts for the Social Sciences. 2nd ed. London: Cambridge University Press.

Ettredge, M., J. Gerdes., and G. Karuga, 2005. "Using Web-based Search Data to Predict Macroeconomic Statistics. Communications of the ACM 48 (11): 87-92.

Floridi, L. 2012. "Big Data and Their Epistemological Challenge." Philosophy \& Technology 25 (4): 435-7.

Fondeur, Y., and F. Karamé. 2013. "Can Google Data Help Predict French Youth Unemployment?" Economic Modelling 30: 117-25.

Hollis, M. 1994. The Philosophy of Social Science: An Introduction. Cambridge Introductions to Philosophy. London: Cambridge University Press.

Hosni, H., and A. Vulpiani. 2017. "Forecasting in Light of Big Data." Philosophy \& Technology.

Jarvie, I. C., and J. P. Zamora Bonilla, eds. 2011. The SAGE Handbook of the Philosophy of Social Sciences. London: SAGE.

Kaldis, B., ed. 2013. Encyclopedia of Philosophy and the Social Sciences. Volume 2. London: SAGE.

Kincaid, H., ed. 2012. The Oxford Handbook of Philosophy of Social Science. Oxford: Oxford University Press.

Kitchin, R. 2014. "Big Data, New Epistemologies and Paradigm Shifts." Big Data \& Society 1 (1): 205395171452848.

Kitchin, R., and G. McArdle. 2016. "What Makes Big Data, Big Data? Exploring the Ontological Characteristics of 26 Datasets." Big Data \& Society, 3(1):205395171663113.

Leney, T. 2004. Finnish. Teach Yourself. Chicago, IL: McGraw-Hill. 
Leonelli, S. 2014. "What Difference Does Quantity Make? On the Epistemology of Big Data in Biology." Big Data \& Society, 1(1).

Little, D., ed. 1995. On the Reliability of Economic Models: Essays in the Philosophy of Economics. Volume 42. Germany: Springer Science \& Business Media.

Mantzavinos, C., ed. 2009. Philosophy of the Social Sciences: Philosophical Theory and Scientific Practice. Cambridge: Cambridge University Press.

Martin, M., and L. C. McIntyre, eds. 1994. Readings in the Philosophy of Social Science. Cambridge, MA: MIT Press.

McIntyre, L., and A. Rosenberg, eds. 2017. The Routledge Companion to Philosophy of Social Science. London: Routledge.

Moffatt, P. G. 2016. Experimetrics: Econometrics for Experimental Economics. London: Palgrave.

Papacharissi, Z. 2010. A Private Sphere: Democracy in a Digital Age. Cambridge: Polity.

Papacharissi, Z. 2015. "Affective Publics and Structures of Storytelling: Sentiment, Events and Mediality." Information, Communication \& Society 19 (3): 307-24.

Pietsch, W. 2015. "Aspects of Theory-ladenness in Data-intensive Science." Philosophy of Science 82 (5): 905-16.

Pietsch, W. 2016. "The Causal Nature of Modeling with Big Data." Philosophy \& Technology, 29 (2): 137-71.

Rosenberg, A. 2016. Philosophy of Social Science. 5th ed. London: Taylor \& Francis.

Steel, D., and F. Guala, eds. 2011. The Philosophy of Social Science Reader. London: Routledge.

Turner, S. P., and P. A. Roth, eds. 2003. The Blackwell Guide to the Philosophy of the Social Sciences. Malden, MA: Blackwell Publishing. 
